\title{
TRADUÇÃO COMO PONTE PLÁSTICA ${ }^{\mathrm{i}}$
}

\section{TRANSLATION AS A PLASCTIC BRIDGE}

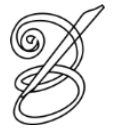 \\ Patrick Rezende ${ }^{\mathrm{ii}}$ \\ Mestre em Estudos Linguísticos \\ Programa $5^{\text {a }}$ habilidade/UFES/Vitória/ES/BRASIL \\ patrickrezende@hotmail.com
}

Grande, no homem, é ser ele uma ponte e não um objetivo: o que pode ser amado, no homem, é ser ele uma passagem e um declínio. Nietzsche em Assim Falou Zaratustra.

Resumo: Este trabalho é uma tentativa de cruzar as vozes daqueles que vêm repensando os processos de tradução como possibilidade de desconstruir o logocentrismo e a visão cartesiana de mundo. Como uma forma de romper com as oficialidades no contar das histórias de aqui e de acolá, refletir-se-á como a tradução pode ser a possibilidade de encontros, que chamaremos de plásticos, que produzam novos textos e contextos, constituindo o traduzir não como um ato de reprodução mimética de um original, mas criação que permite sobrevida, espaço que estende as fronteiras e abre possibilidades para a produção de mais significados.

Palavras-chaves: Tradução; Desconstrução, Pontes Plásticas.

Abstract: This paper is an attempt to cross voices of those who are presently rethinking the process of translation as a way of deconstructing logocentric and Cartesian worldviews. Breaking away from the official pressures of telling stories from here and there in a specific way, we will reflect on how translation may engender possibilities of encounters, always plastic, producing new texts and contexts, translating not a mimetic reproduction of an original, but as a form of creating an afterlife, a space where boundaries are stretched and new possibilities of interpretation are opened.

Keywords: Translation; deconstruction, plastic bridges.

I ninterruptamente passamos nossas vidas permeados por fontes constitutivas, estas que cruzam, contaminam e formam nossas histórias. As referências midiáticas, as instituições religiosas e as de ensino, as organizações políticas e econômicas, os núcleos familiares e os mecanismos sociais são pontos cardiais, principalmente no Ocidente, na construção da memória de um povo. As tradições são constituídas e mantidas graças ao esforço, de certa forma, coletivo, de diversos níveis de organizações. Sendo que nesse contar da história, muitas destas fontes constitutivas acabam por se incluírem na privilegiada posição de oficiais. Assim, é importante refletir como escolas, igrejas, governos, imprensa e outras estruturas acabam por obter uma oficialidade, tornando-se àqueles que contam a história, única e oficial. 
O Ocidente, entendido aqui como um constructo que vai além da delimitação geográfica e que abarca sociedades mediadas por práticas normatizantes, opressoras e dominantes, tem se sustentado por séculos, em muitos aspectos, na dialética helênica, mais precisamente em conceitos platônicos.

Na obra A República (1993), Platão insere Sócrates como personagem principal de diálogos que se tornaram importantes pilares para toda a filosofia ocidental. Por meio de diálogos, o filósofo grego sujeita seus principais conceitos, entre eles: a idealização da cidade, o que é um filósofo, a questão da justiça, o célebre Mito da Caverna e a questão da mimesis, entre outras considerações.

Durante a obra, o uso de mimesis é marcado por grande variedade de aplicações. Há momentos em que o conceito se restringe à poesia, ou ao tipo de poesia representado pela comédia e pela tragédia, ou seja, quando o poeta/indivíduo pronuncia determinado discurso como se fosse outra pessoa. Entretanto, a noção de mimesis que interessa a este trabalho é aquela que pode ser expandida à questão filosófica, em outras palavras, a ideia de criação como imitação. Para Platão, até o mundo físico não passa de uma imitação de verdadeiros 154 conceitos presente no mundo das ideias, ou seja, uma criação de segunda mão.

Desta forma, retomando A República, Luís Eustáquio Soares (2012) explica que o filósofo grego, ao pensar na cidade ideal, faz um paralelo com o corpo humano em postura vertical e o divide em três, considerando hierarquicamente cada parte. Desta forma, tem-se o mundo ideal, o mundo da cópia e o mundo do simulacro, correspondidos paralelamente às partes alma-cabeça, alma-peito e alma-ventre.

Paralelo ao que ficou conhecido como mundo platônico, ou seja, o perfeito, a origem, tem-se o que Platão veio a chamar de alma-cabeça. Seguindo a comparação com o corpo humano, tem-se o peito, onde se localiza o coração, ou melhor, a alma-peito, que "nada mais é que nosso mundo, tudo que existe no nosso mundo, sendo simplesmente, assim, isto a que chamamos de realidade." (SOARES, 2012, p.147). Desta forma, observando o diagrama é possível inferir então que o mundo em que estamos implantados, ou melhor, a realidade na qual estamos inseridos é uma reprodução, uma memória do que seria o mundo ideal.

Abaixo da alma-peito, tem-se a alma-ventre que Soares ressalva como a parte que nos insere no mundo animal, “a cópia da cópia, o inverso do mundo ideal, representando, nesse sentido, tudo o que devemos evitar, a fim de nos aproximarmos, durante nossa existência, do mundo ideal, do mundo das essências." (2012, p. 147). 
A divisão platônica, tão bem traduzida por Soares, expõe lucidamente como a conjuntura global ainda na atualidade se configura de tal maneira. As ideias expostas em $A$ República, por esta perspectiva, assumem grande influência na constituição do olhar ocidental.

\footnotetext{
Claro está - daí a importância de dividir o corpo humano em três partes, verticalmente - que a divisão platônica do corpo humano é antes de tudo uma divisão política, para não dizer fascista, ou fascistoide, porque tudo aquilo que, aos olhos de Platão, deve ser evitado, que perturba ou pode perturbar a "ordem" da cidade, deve ser lançado no "quarto do despejo" da alma-ventre, deve ser simulacro, cópia da cópia, sendo compreendido como coisas que estão numa posição antípoda do mundo ideal, das essências imutáveis. (SOARES, 2012, p.147)
}

Transpondo a tripartição do corpo por Platão junto com seus paralelismos de mundos para a problemática da estabilidade das ditas fontes oficiais, pode-se inferir que os conceitos de origem, original e oficial, tão presentes na nossa tradição ocidental, se cruzam na questão mimética exposta acima. Ou seja, os detentores das tecnologias de poder se posicionam na privilegiada posição de cópia, em outras palavras, fingem-se capazes de reproduzir fidedignamente as condições de suposto mundo ideal e alocam os que não se enquadram nos paradigmas de seus interesses no mundo do simulacro, isto é, representações que por si já são cópia.

Se mimesis é representação, e se, no espaço da alma-peito, temos representação, porque temos cópia, então acho perfeitamente compreensível deduzir que, aos olhos de Platão, mimesis ideal seria aquela que fosse ou procurasse imitar, fazer-se como cópia do mundo ideal, do mundo das essências, que nada mais é do que o mundo dos poderes, ou dos poderosos, os quais tendem a se apresentar como sendo os ideais, os perfeitos, os intocáveis, os inimitáveis imitáveis, com o perdão do oximoro. (SOARES, 2012, p.149)

Levando em consideração a filosofia platônica, o que está fora das oficialidades é entendido como mal acabado, danoso, maléfico, capaz de corromper a constituição do suposto mundo ideal. Assim, valem-se de discursos maniqueístas que visam um bem estar universal para justificar processos que impõem suas perspectivas sobre a do outro, põem-se na decisão do que e de que forma traduzir, sempre favorecendo sua posição e atribuindo a quaisquer outras possibilidades a marca do simulacro. Entretanto, é importante notar que as próprias fontes oficiais fingem não perceber que elas próprias são cópias, apenas versões de determinados posicionamentos, e na ausência inequívoca de um mundo concreto das ideias colocam-se na posição de alma-cabeça, ou seja, exemplos a serem copiados e reproduzidos. 
A tradução, nesta perspectiva, passa a ser ferramenta de manutenção de determinadas práticas e acaba por produzir um mundo dicotômico, permeado por tradições, como bem salienta Hobsbawn (2002), muitas vezes inventadas. Ou seja, conjuntos de práticas, simbólicas ou rituais, que manifestam determinados valores e normas de comportamento, sendo que, a partir de sua intensa repetição, passam a ser assimiladas como se houvessem uma perfeita relação com o passado, ainda que sejam práticas recentes. Em outras palavras, a repetição de determinado ato sobreposto a uma relação artificial com o passado, transforma algo recente em uma tradição histórica, legitimando determinados valores que passam a ser aceitos pela maioria, bem como incorporando costumes de interesse do grupo dominante.

“A representação da tradição, materializada nas artes, nos costumes e, principalmente, nas traduções, leva adiante ideias e impérios” (DEPAULA, 2011, p.77). De tal forma, a tarefa tradutória se estabelece como prática aliada aos grupos dominantes, que a entende como a reprodução mimética de um original, sendo esta possibilidade nunca alcançada plenamente. $\mathrm{O}$ produto, ou seja, a tradução é vista sempre como menor.

Para clarificar, podemos retomar Bassnett (2008) que pontua que a tradução foi e vem 156 sendo explicitamente usada como ferramenta do poder colonial, instrumento empregado para silenciar vozes e reforçar hierarquias de poder. O discurso colonial consecutivamente se valeu da tradução para transformar valores de seus interesses em verdades universais. Foucault em seu prestigiado A ordem do discurso (2010) pontua que o fato de não haver limites para os discursos faz emergir um ameaçador dispositivo de poder: as suas reproduções sem quaisquer questionamentos, criando um perigoso processo de normatização do discurso. Exemplifico com os discursos utilizados pelas nações imperialistas, que se valem de pretextos civilizatórios para justificarem práticas de violência. Tais retóricas são muitas vezes absorvidas e reproduzidas pelas próprias populações subordinadas. Desta forma, retomando o filósofo francês, "o discurso não é simplesmente aquilo que traduz as lutas ou os sistemas de dominação, mas aquilo por que, pelo que se luta, o poder do qual nos queremos apoderar." (FOUCAULT, 2010, p.10)

Assim, faz-se mister entender que a tradução por ser uma prática que lida com a constituição de significados. Revela-se um exercício de poder, já que o significar gera conflitos de compreensão, de formação de pensamento e também de interesses políticos, econômicos e sociais. A tradução tem a capacidade de transformar o outro para além do estritamente linguístico, pois os processos de formação de identidade perpassam a linguagem. 
Consequentemente, ao se traduzir o outro é possível que sua própria identidade seja também modificada e que se alterarem suas funções em diferentes contextos, adequando o outro aos interesses próprios de cada conjuntura, podendo o traduzir ser visto como um processo de reescritura como aponta Frota (1999).

Para que não nos posicionemos passivamente com relação aos processos tradutológicos que são também constitutivos, precisamos refletir sobre as concepções de tradução presentes e repensar nosso entendimento sobre elas. Portanto, para a autora indiana Tejaswini Niranjana (1992),

Repensar a tradução torna-se uma importante tarefa num contexto onde ela tem sido usada, desde o Iluminismo Europeu, para subscrever práticas de subjetivação, especialmente para os povos colonizados. Tal atitude - um exercício de grande urgência para uma perspectiva pós-colonial que busca compreender "sujeitos" já inseridos "em tradução", apresentados e reapresentados a partir da visão colonialista - busca recuperar a noção de tradução através de sua desconstrução e reescrever seu potencial como uma estratégia de resistência. (NIRANJANA, 1992, p. 6, tradução nossa) $)^{\mathrm{iii}}$

Entender as forças que estão inseridas no extenso processo de tradução é ter o poder de se posicionar a partir de suas próprias perspectivas. É também entender que o que é oficial é tão volátil quanto a própria palavra, que a cada uso ganha um novo sentido. Ao mesmo tempo, abarca todos os outros remanescentes, como no livro de fantasia The Hobbit, do aclamado J.R.R. Tolkien, onde o personagem Bilbo diz "Bom dia!" a Gandalf e este responde:

\footnotetext{
- O que você quer dizer com isso? - perguntou ele. - Está me desejando um bom dia, ou quer dizer que o dia está bom não importa que eu queira ou não, ou quer dizer que você se sente bem neste dia, ou que este é um dia para se estar bem?

- Tudo isso de uma vez - disse Bilbo. (TOLKIEN, p.5, 2003)
}

A belíssima passagem transcrita acima traduz magistralmente como uma mera expressão pode dar lugar a várias possibilidades de entendimento. De fato, um significado não está em direta correspondência com um significante, mas em um devir. Rajagopalan (2000) pontua que, graças à tradução, é possível continuamente reescrever, recriar e reinventar as histórias.

Esse reposicionamento da tradução, esse novo olhar, pode ser visto como uma possibilidade de questionar e desconstruir as maneiras de entendimento da questão da representação. Derrida nos leva a discutir as ideias de origem e original, e consequentemente, oficial, como bem apontado por Niranjana. 
A crítica de Derrida à representação, por exemplo, permite-nos questionar a noção de (re)presentação e, portanto, é a própria noção de uma origem ou um original que precisa ser (re)presentado. Derrida argumentaria que a "origem" é em si dispersa e sua identidade indecidível. A representação, assim, não (re)presenta um "original", mas sim, (re)presenta o que já é representado. (NIRANJANA, 1992, p.9, tradução nossa $)^{\text {iv }}$

De tal forma, é preciso abandonar de vez essa lógica de representação que obedece a uma equivalência automática entre significante e significado. Com Derrida (2011), percebemos que o significado é apenas um significante inserido em uma rede infinita de outros significantes, em um verdadeiro processo de iterabilidade, sendo que a cada contexto a significação ganha ilusoriamente um significado novo e ilusório. De fato, como Derrida aponta, não há o significado, apenas significantes remetidos a outros significantes, ou seja, rastros dos rastros em ininterrupto remetimento. Deve-se entender a abolição do significado cautelosamente, já que, na verdade, abolir o significado para Derrida é pensá-lo como significante, deslocá-lo para uma teia constituída por referências. É revogar a ideia de um significado que se autoconstitui, como algo que existe em si próprio, fora da conjuntura no qual está inserido, seja linguística ou apenas conceitual. Por isto, “todo processo é ilusório, ilusão necessária para se produzir linguagem, para que o texto se apresente; na verdade, todo processo é um jogo, e cada jogo tem suas próprias regras, que servem apenas para aquele jogo e não para outro.” (GRIGOLETTO, 2003, p.32)

Portanto, neste espaço, neste entrelugar em meio à ilusão do condicionamento do sentido e sua emancipação, que se produz no jogo descrito por Derrida, é que pode se localizar o tradutor, como aquele que constrói pontes, estas plásticas, que visam possibilidades de descolamento do sujeito, não apenas entre o eu e o outro, mas entre os eus presentes no sujeito e os outros envoltos na conjuntura na qual o individuo está inserido.

É necessário marcar que muito vem escapando da lógica platônica ainda tão arraigada no mundo, sobretudo na perspectiva do Ocidente. A tradução, então ferramenta de manutenção das hierarquias, passa a ser usada contra esta própria lógica helênica, como um cavalo de troia que penetra os muros ocidentais, dando voz aos que vêm sendo silenciados, permitindo as então fontes não oficiais de também serem inseridas e ouvidas.

Reposicionar o olhar, desconstruir perspectivas e refletir sobre as práticas tradutológicas é uma tentativa de romper com as oficialidades do discurso e com a constituição binária e cartesiana do mundo. Assim, entendo que o que vemos, sentimos e 
presenciamos é sempre apenas uma imagem, que não conta mil histórias, mas sim uma versão de mil histórias.

De tal forma, Arrojo nos lembra que Nietzsche dá outra definição ao conceito de verdade, entendendo-a como

[...] uma soma de relações humanas que se tornaram poética e retoricamente intensificadas, metamorfoseadas, adornadas e, depois de muito uso, parecem, para uma nação, fixas, canônicas e obrigatórias: as verdades são ilusões, das quais nos esquecemos que são ilusões; metáforas gastas que se tornaram impotentes para afetar os sentidos; moedas que perderam sua efígie e agora só entram em consideração como metal, não mais como moedas. (apud ARROJO, 2003, p.17)

De tal modo, Nietzsche nos lembra que a verdade é plástica, que a ideia de constituição de um conceito fixo é fantasia e que o conceito de verdade que possuímos hoje não é mais do que uma ilusória convenção estipulada pelas tecnologias de poder. Assim, Arrojo indica que a reflexão de Nietzsche sobre a questão da verdade implica desconstruir a "noção clássica de literalidade, ou seja, da possibilidade de um significado depositado na letra, anterior ou imune à interpretação de um sujeito. Aquilo que consideramos a coisa-em-si 'designa apenas as relações das coisas aos homens"” (ARROJO, 2003, p.17).

A tradução é tida como ponte plástica neste momento em que o homem compreende que as coisas se tornam o que são a partir da relação dialógica entre indivíduo e objeto, lembrando que é plástica exatamente por ser moldável e receber diferentes formas a cada contexto. Nietzsche nos conscientiza da metaforicidade da língua. Portanto, o indivíduo se vale a todo instante de processos de tradução para decodificar o mundo no qual está inserido. Todavia, este deciframento é maleável, uma vez que a correspondência entre significante e significado não é pré-estabelecida preestabelecida e ocorre na relação intersubjetiva momentânea, já que, como supracitado, somos afetados continuamente de maneiras diversas. Com isso, "a desconstrução da autonomia do sujeito consciente solapa todo o projeto logocêntrico e qualquer possibilidade de uma relação puramente objetiva entre o homem e a realidade" (ARROJO, 2003, p.17). Ela valora as infindas possibilidades de representações e constituições do sujeito, o que pode vir a ser entendido como uma forma de reposicionar o olhar para algo além das dicotomias presentes nos paradigmas ocidentais.

Conceber a ideia da tradução como uma ponte plástica pode vir a ser uma forma de desconstruir os pilares estruturais de hierarquização do mundo, levando-nos a compreender 
que as relações não são fixamente duais, mas coexistentes e plurais. A partir desta perspectiva, a tradução pode ser entendida como

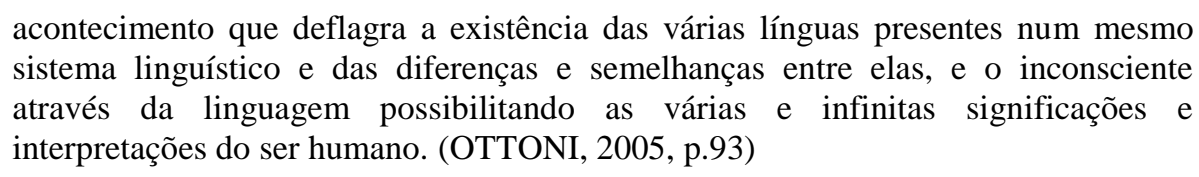

A tradução, assim, na sua plasticidade, promove pontes que manifestam os cruzamentos existentes nas línguas, consequentemente, evidenciando o homem como cruzamento de diversos sujeitos.

\section{REFERÊNCIAS BIBLIOGRÁFICAS}

ARROJO, Rosemary (Org.). O signo desconstruído: implicações para a tradução, a leitura e o ensino. Campinas, SP: Pontes, 2003

BASSNETT, Susan. Translation Studies. Routledge, 2008

DEPAULA, Lillian. A invenção do original via tradução, pseudotradução e autotradução. Vitória: EDUFES, 2011.

DERRIDA, Jacques. Gramatologia.Tradução Miriam Chnaiderman e Renato Janine Ribeiro. São Paulo: Perspectiva, 2011.

FOUCAULT, Michel. A Ordem do Discurso: Aula inaugural no Collège de France, pronunciada em 2 de dezembro de 1970. Tradução: Laura Fraga de Almeida Sampaio. 20. ed. São Paulo: Edições Loyola, 2010

FROTA, Maria Paula. Por uma Redefinição de Subjetividade nos Estudos da Tradução. In: Martins, Márcia A.P. (org) Tradução e Multidisciplinaridade. Rio de Janeiro: Lucerna, 1999.

GRIGOLETTO, Marisa. A desconstrução do signo e a ilusão da trama. In: ARROJO, R. (Org.) O signo desconstruído: implicações para a tradução, a leitura e o ensino. Campinas, SP: Pontes, 2003.

NIRANJANA, Tejaswini. Siting Translation: History, Post-Structuralism, and the colonial context. California: University of California Press,1992. 
NIETZSCHE, Friedrich W. Assim falou Zaratustra: um livro para todos e para ninguém. Tradução Paulo César de Souza. São Paulo: Companhia das Letras, 2011

HOBSBAWM, Eric; RANGER, Terence (orgs.). A invenção das tradições. São Paulo: Paz e Terra, 2002.

OTTONI, Paulo. Tradução manifesta: double bind \& acontecimento. Campinas, SP: Editora da Unicamp; São Paulo, SP: Edusp, 2005.

PlATÃO. A República. Trad. M. H. R. Pereira. Lisboa: Fundação Calouste Gulbenkian, 1993.

RAJAGOPALAN, Kanavillil. Pós-modernidade e a tradução como subversão. Transcrito dos Anais do VII Encontro Nacional de Tradução/I Encontro Internacional de Tradução - São Paulo, 1998. Disponível em: http://www.novomilenio.inf.br/idioma/19980911.htm. Acesso em 21 de maio de 2013.

SOARES, Luís Eustáquio. América Latina, literatura e política: abordagens transdiciplinares. Vitória: Edufes, 2012.

TOLKIEN, John Ronald Reuel. O Hobbit. Tradução Lenita Maria Rímoli Esteves. São Paulo: Martin Fontes, 2003. Disponível em: http://ebookwf.com/wpcontent/uploads/2012/01/O-Hobbit-J.R.R-Tolkien.pdf. Acesso em 21 de maio de 2013.

RECEBIDO EM 25/06/2014

ACEITO EM 12/08/2014

\footnotetext{
' Trabalho apresentado no GT Estudos da Tradução no Encontro Nacional da ANPOLL 2014

${ }^{i i}$ Lattes: http://lattes.cnpq.br/2160251766620192

iii "The rethinking of translation becomes an important task in a context where it has been used since the European Enlightenment to underwrite practices of subjectification, especially for colonized peoples. Such a rethinking- a task of great urgency for a post-colonial theory attempting to make sense of "subjects" already living "in translation", imaged and re-imaged by colonial ways of seeing- seeks to reclaim the notion of translation by deconstructing it and reinscribing its potential as a strategy of resistance."

iv "Derrida's critique of representation, for example, allows us to question the notion of re-presentation and therefore the very notion of an origin or an original that needs to be re-presented. Derrida would argue that the "origin" is itself dispersed, its "identity" undecidable. A representation thus does not re-present and "original"; rather, it re-presents that which is always already represented.
} 